\title{
Oued Bouhlou: A new hope for the Moroccan pearl mussel
}

\author{
Ronaldo Sousa $^{1}$ (D) | Amílcar Teixeira ${ }^{2}$ | André Santos ${ }^{1}$ | Hassan Benaissa ${ }^{3}$ | \\ Simone Varandas ${ }^{4}$ | Mohamed Ghamizi ${ }^{3}$ | Vincent Prié ${ }^{5}$ | Elsa Froufe ${ }^{6}$ | Manuel Lopes-Lima ${ }^{7}$
}

${ }^{1}$ CBMA - Centre of Molecular and Environmental Biology, Department of Biology, University of Minho, Braga, Portugal

${ }^{2}$ CIMO-ESA-IPB - Mountain Research Centre, School of Agriculture, Polytechnic Institute of Bragança, Bragança, Portugal

${ }^{3}$ Muséum d'Histoire Naturelle de Marrakech, Université Cadi Ayyad, LHEAC, FSSM,

Marrakech, Morocco

${ }^{4}$ CITAB-UTAD - Centre for Research and Technology of Agro-Environment and Biological Sciences, Forestry Department, University of Trás-os-Montes and Alto Douro, Vila Real, Portugal

${ }^{5}$ Biotope, Mèze, France

${ }^{6}$ CIIMAR/CIMAR - Interdisciplinary Centre of Marine and Environmental Research, University of Porto, Matosinhos, Portugal

${ }^{7} \mathrm{CIBIO} / \mathrm{InBIO}$ - Research Center in

Biodiversity and Genetic Resources, University of Porto, Vairão, Portugal

\section{Correspondence}

Ronaldo Sousa, CBMA - Centre of Molecular and Environmental Biology, Department of Biology, University of Minho, Campus Gualtar, 4710-057 Braga, Portugal.

Email: rg.eco.sousa@gmail.com

\section{Funding information}

Mohamed bin Zayed Species Conservation Fund, Grant/Award Number: Reference 15256799; IUCN SOS Save our Species fund, Grant/Award Number: Reference 2015B-015; Portuguese Foundation for Science and Technology, Grant/Award Number: SFRH/BPD/108445/2015 (EF) and SFRH/ $\mathrm{BD} / 115728 / 2016$ (MLL)

\section{Abstract}

1. The freshwater pearl mussel Margaritifera marocana (Pallary, 1918) is an endemic species of Morocco being listed as critically endangered and it stands among the world's 100 most threatened species. An extensive survey was performed in the Sebou basin (total area of approximately 40,000 $\mathrm{km}^{2}$ ), covering 26 different sites. Margaritifera marocana was found only in four sites limited to a small tributary (Oued (=River) Bouhlou).

2. This population has a very restricted distribution (no more than $4 \mathrm{~km}$ of river length) but appears stable with recent recruitment, since small specimens were found.

3. Genetic analyses were performed, showing that this population has a similar diversity to that found in the River Laabid (Oum Er Rbia basin), but represents a distinct conservation unit that should be managed independently.

4. Although this study adds a new population to the current known distribution of M. marocana, urgent conservation measures (e.g. extension of the Tazzekka National Park; better management of river flow; increase of the riparian vegetation in some stretches; establishment of national and international legislation, and engagement of local citizens) are needed given the species' restricted distribution, its rarity, and the numerous threats that impair its future survival.

\section{KEYWORDS}

conservation, freshwater mussels, genetic diversity, Margaritifera marocana, Sebou basin, Unionida

\section{1 | INTRODUCTION}

Freshwater mussels (Order Unionida) form a charismatic and highly threatened faunal group depending on fish to complete their life cycle (i.e. their larvae (glochidia) need a host to metamorphose into a juvenile; Lopes-Lima et al., 2014). In recent years, numerous studies have been conducted on these organisms with respect to their taxonomy, phylogeny, biogeography, ecology and conservation (Lopes-Lima, Froufe, et al., 2017; Lopes-Lima, Sousa, et al., 2017; Strayer et al., 2004; Zieritz et al., in press). However, these studies were mainly conducted in North America and Europe and there are still many gaps for species native to South America, Africa and Asia (Lopes-Lima et al., 2014; Zieritz et al., 2016).

In Africa, 87 unionid species have been described (Graf \& Cummings, 2011); one of these is Margaritifera marocana. This species is endemic to Morocco, listed as critically endangered by IUCN, and is classified among the world's 100 most threatened species (Baillie \& Butcher, 2012). In a recent study, Sousa et al. (2016) conducted an extensive sampling campaign to assess the conservation status of $M$. marocana in the Oum Er Rbia basin. In that study, the authors confirmed 
the presence of this species, but only the River ('Oued' in Arabic) Laabid contains a stable and recruiting population. In other rivers surveyed, the species was found to have a very low abundance and restricted spatial distribution (River Oum Er Rbia) or it was not possible to confirm its occurrence, despite earlier studies describing its presence (River Derna; Araujo, Toledo, Van Damme, Ghamizi, \& Machordom, 2009).

Earlier studies or specimens available in museums also confirm the presence of M. marocana in the Sebou basin. However, most of these studies are outdated and given the number of threats that this species is exposed to (extensively reviewed in Sousa et al., 2016), many of these earlier described populations are possibly now extinct. The aims of this study were: (i) to detect the presence of populations in the Sebou basin; (ii) to assess basic ecological characteristics such as distribution, abundance and population structure; and (iii) to characterize and compare the genetic diversity of the newly discovered population in the Sebou basin with the M. marocana populations previously described in the Oum Er Rbia basin.

\section{2 | MATERIAL AND METHODS}

The River Sebou is $450 \mathrm{~km}$ long and its basin covers an area of approximately $40000 \mathrm{~km}^{2}$, totally in Morocco. This basin is one of the most populated in Morocco and the economic activity is dominated by agriculture, industry, forestry and tourism. The average annual rainfall in the basin is about $600 \mathrm{~mm}$ (ranging from more than $1200 \mathrm{~mm}$ to less than 400 mm; Shahin, 2002).

Assessment of M. marocana in the Sebou basin was carried out between 2014 and 2016 at 26 sites in the rivers Abiod (three sites), Ait Hamza (one site), Beth (four sites), Bouhlou (eight sites), El Bayad (two sites), Ouergha (one site), Redom (five sites) Sebou (one site) and Tghat (one site) (Figure 1). At each site, a river stretch (minimum $100 \mathrm{~m}$ ) was surveyed covering different habitats (i.e. riffles and pools, banks and centre of the channel) using the methods described in Sousa et al. (2016). In summary, these surveys were undertaken by three divers, and freshwater mussels were detected visually or by searching through the bottom by hand. In total, $6 \times 15$ min replicate surveys were carried out (i.e. 90 min of survey time per site). Abundance per site was recorded as the total number of individuals found in $15 \mathrm{~min}$ per person and represented by the number of individuals per catch per unit effort (ind. CPUE). Shell length was measured to the nearest $0.1 \mathrm{~mm}$ with Vernier calipers and these data were used to infer population structure.

For molecular analyses, small foot samples of 19 M. marocana found in the River Bouhlou were non-lethally excised following Naimo,
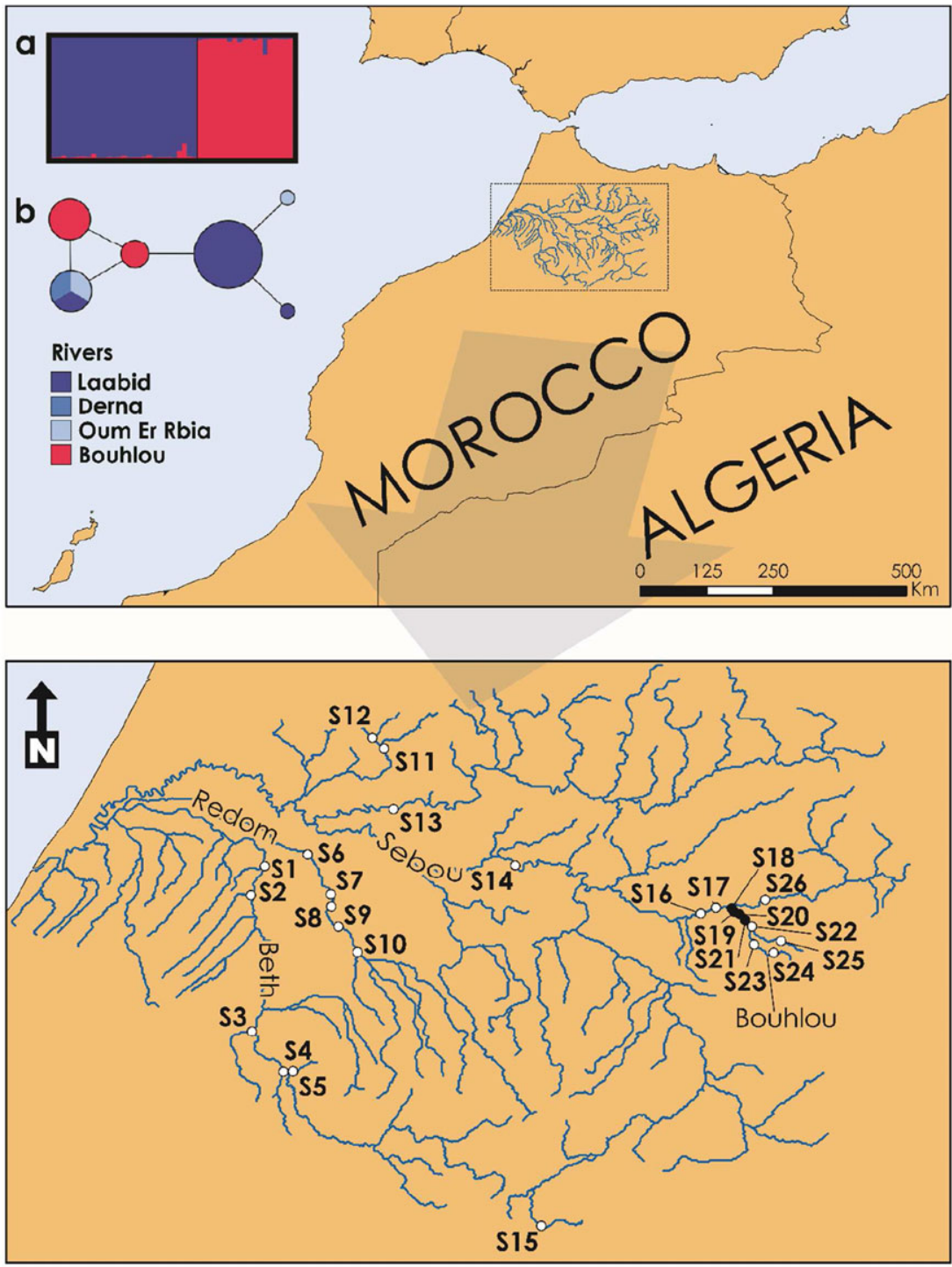

FIGURE 1 Map of the river Sebou basin showing the locations of the 26 sampling sites. Black dots represent sites with mussels and white dots sites without mussels. Results of the microsatellites' STRUCTURE Bayesian clustering analysis on M. marocana populations with the most likely number of clusters $(K=2)$. Each individual is represented by a vertical bar in $\mathrm{K}$ coloured segments with the length of each bar being proportional to the estimated membership coefficient. Black lines separate individuals from the two different populations (a); and COI haplotype (TCS) network showing the relationships of $M$. marocana individuals. Circle size is proportional to the observed haplotype frequencies and colours represent the four populations analysed (b) 
Damschen, Rada, \& Monroe (1998) and placed directly into 96\% ethanol. All 19 specimens were carefully returned to the river in their original position after sampling. Total genomic DNA was extracted using a standard high-salt protocol as described by Sambrook, Fritsch, and Maniatis (1989). Nine microsatellites previously used for $M$. marocana were scored for the new individuals, following Sousa et al. (2016).

Allelic diversity, observed $\left(\mathrm{H}_{\mathrm{O}}\right)$ and expected $\left(\mathrm{H}_{\mathrm{E}}\right)$ heterozygosity, and inbreeding coefficients $\left(F_{I S}\right)$ were estimated in GENETIX v.4.05 (Belkhir, Borsa, Chikhi, Raufaste, \& Bonhomme, 2004) while deviations from Hardy-Weinberg equilibrium (HWE) were tested using GENEPOP v.4.1 (Raymond \& Rousset, 1995) with 10000 iterations. Population structure was analysed using the Bayesian model-based clustering approach implemented in STRUCTURE v.2.3.4 (Pritchard, Stephens, \& Donnelly, 2000), also including the previously scored individuals from the River Laabid (Sousa et al., 2016). Fifteen independent runs were made for each number of clusters $(K)=1-4$, with each run consisting of a burn-in of $10^{5}$ Markov-chain Monte Carlo steps followed by $5 \times 10^{5}$ steps. The most likely $K$ was selected using the $\Delta K$ method described in Evanno, Regnaut, \& Goudet (2005) and implemented in STRUCTURE HARVESTER v0.6.94 (Earl \& von Holdt, 2012). Values from different run replicates for each value of $\mathrm{K}$ were averaged in CLUMPP v1.1.2 (Jakobsson \& Rosenberg, 2007) and summary outputs were displayed graphically in DISTRUCT v1.1 (Rosenberg, 2004).

Five samples from the River Bouhlou were also amplified for the F-type mtDNA cytochrome oxidase subunit 1 gene (COI; c. 700 BP fragment), with LCO_22me and HCO_700dy primers (Walker et al., 2006, 2007), following PCR conditions described in Froufe et al. (2014) with annealing temperature of $55^{\circ} \mathrm{C}$. Sequences were obtained using the BigDye sequencing protocol (Applied Biosystems 3730xl) by Macrogen Inc., Korea. Forward and reverse sequences were edited and assembled using ChromasPro 1.7.4 (Technelysium, Tewantin), and the alignment built with ClustalW in Bioedit 7.2.5 (Hall, 1999), including one sequence from the River Derna, seven from the Laabid and two from the Oum Er Rbia, all from the Oum Er Rbia basin (GenBank: EU429676-EU429685; Araujo et al., 2009). To evaluate the relationships among all the haplotypes obtained, sequences were joined in a statistical parsimony network constructed under a 95\% criterion using TCS 2.1 (Clement, Posada, \& Crandall, 2000) and visualized with tcsBU (Múrias dos Santos, Cabezas, Tavares, Xavier, \& Branco, 2016).

\section{3 | RESULTS}

From the 26 different sites surveyed in the Sebou basin, specimens were found in only four sites located in the lower section (from the mouth to $4 \mathrm{~km}$ upstream) of the River Bouhlou (Figure 1) with S18 presenting an average $( \pm S D)$ abundance of $3.3( \pm 1.0)$ ind. CPUE, S19 of $2.2( \pm 1.2)$ ind. CPUE, S20 of $3.0( \pm 0.9)$ ind. CPUE and S21 of 0.3 $( \pm 0.5)$ ind. CPUE. In these four sites, shell length varied from 52 to $122 \mathrm{~mm}$ with an average $( \pm \mathrm{SD})$ value of $86.6 \pm 18.9 \mathrm{~mm}$ (Figure 2). Interestingly, the population in the River Bouhlou contains a high proportion of juveniles with $70 \%$ of the measured individuals smaller than $100 \mathrm{~mm}$ (with $11 \%$ of the individuals smaller than $60 \mathrm{~mm}$ ).

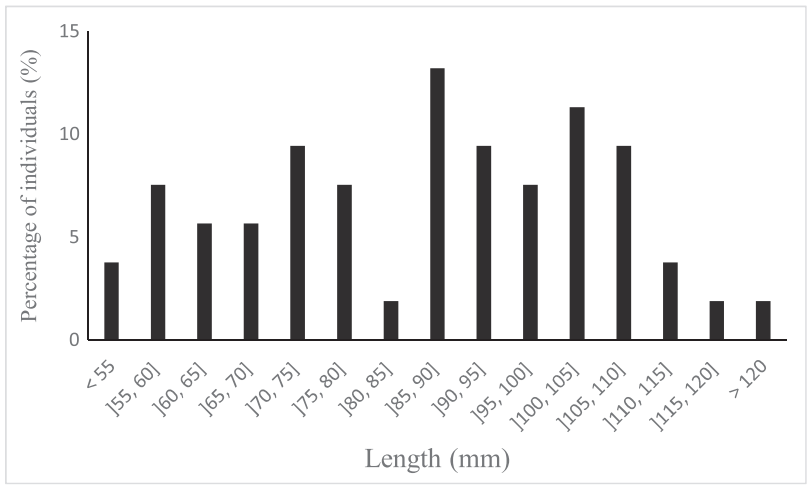

FIGURE 2 Population structure of Margaritifera marocana in the River Bouhlou $(N=53)$

From the nine microsatellites used, three have been previously reported as monomorphic in the Laabid population (Sousa et al., 2016). However, in the Bouhlou population, one of these (Marma4726) was found to have two distinct alleles (Table 1) raising the number of polymorphic markers to seven. The total number of observed alleles in the Bouhlou was 75 - an increase from the 15 previously scored from the Laabid population (Sousa et al., 2016), ranging from two (Marma4322 and Marma4726) to 22 (Marma4277) per locus (Table 1). All microsatellites are in Hardy-Weinberg equilibrium, presenting an overall $\mathrm{H}_{\mathrm{O}}$ of $0.37\left(\mathrm{H}_{\mathrm{E}}\right.$ : 0.36) and with an unexpected very low overall $F_{I S}$ of -0.01 (Table 2). STRUCTURE analysis indicated that two $(K=2)$ is the most likely number of clusters present, corresponding to the two populations analysed, i.e. the rivers Bouhlou and Laabid (Figure 1a).

TABLE 1 Characteristics of nine microsatellite loci in Margaritifera marocana; $\mathrm{Na}=$ number of observed alleles per locus; sizes of amplified fragments; $H_{E}=$ mean expected heterozygosity; $H_{O}=$ mean observed heterozygosity; $F_{\mathrm{IS}}=$ mean inbreeding coefficient; HWE = HardyWeinberg deviation $(P)$

\begin{tabular}{lllllll} 
Locus & $\mathrm{N}_{\mathrm{A}}$ & Allele size range (bp) & $\mathrm{H}_{\mathrm{E}}$ & $\mathrm{H}_{\mathrm{O}}$ & $F_{\mathrm{IS}}$ & HWE \\
\hline Marma1632 & 1 & - & - & - & - & - \\
\hline Marma3621 & 1 & - & - & - & - & - \\
\hline Marma4143 & 17 & $240-292$ & 0.79 & 0.81 & 0.02 & 0.13 \\
\hline Marma4277 & 22 & $311-359$ & 0.75 & 0.85 & 0.12 & 0.29 \\
\hline Marma4315 & 7 & $186-198$ & 0.18 & 0.40 & 0.54 & - \\
\hline Marma4322 & 2 & $236-238$ & 0.12 & 0.15 & 0.19 & 0.61 \\
\hline Marma4726 & 2 & $164-166$ & 0.11 & 0.10 & -0.10 & - \\
\hline Marma4859 & 16 & $177-223$ & 0.86 & 0.85 & 0.01 & 0.75 \\
\hline Marma5167 & 7 & $134-146$ & 0.36 & 0.36 & 0.00 & - \\
\hline
\end{tabular}

TABLE 2 Microsatellite statistics for Margaritifera marocana populations; $N$ = number of samples; $N_{A}=$ number of observed alleles per population; $N_{P A}=$ Number of private alleles per population; $H_{E}=$ mean expected heterozygosity; $H_{O}=$ mean observed heterozygosity;

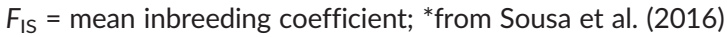

\begin{tabular}{lllllll} 
Population & $\mathrm{N}$ & $\mathrm{N}_{\mathrm{A}}$ & $\mathrm{N}_{\mathrm{PA}}$ & $\mathrm{H}_{\mathrm{E}}$ & $\mathrm{H}_{\mathrm{O}}$ & $\mathrm{F}_{\mathrm{IS}}$ \\
\hline Bouhlou & 19 & 30 & 13 & 0.36 & 0.37 & -0.01 \\
Laabid* & 29 & 63 & 45 & 0.62 & 0.54 & 0.152
\end{tabular}


At the $95 \%$ confidence limit, TCS produced a single network shown in Figure 1b. From the five new M. marocana sequences analysed (i.e. River Bouhlou), two distinct haplotypes were resolved, one shared between two individuals (GenBank: KY828154) and the other shared among three individuals (GenBank: KY828153). From the three populations in the Oum Er Rbia basin, four haplotypes were recovered, without shared haplotypes between the two basins (Figure $1 \mathrm{~b}$ ).

\section{4 | DISCUSSION}

Historical information on the distribution of M. marocana in the Sebou basin describes this species in the rivers Fes and Redom (Pallary, 1918, 1923,1928 ) and specimens in museums indicate that the species was also present in the rivers Beht, Tiflet and Sebou (Araujo \& Ramos, 2000). The recent survey could not confirm this distribution as no specimens were found in the rivers Beht, Redom and Sebou. In addition, the River Fes is very polluted at present and in many stretches this river is temporary without flow during the summer restricting the presence of $M$. marocana. It was not possible to survey the River Tiflet owing to logistical constraints and so the presence or absence of M. marocana in this tributary still needs to be confirmed. In all the other tributaries surveyed (except the River Bouhlou, see below) no specimens, or even shells, were found.

The abundance and spatial distribution in the Bouhlou was much smaller than in the Laabid (Oum Er Rbia basin) (Sousa et al., 2016). Indeed, in the River Laabid, individuals were recorded over more than $50 \mathrm{~km}$ of river length, and abundances were as high as 30.0 ind. CPUE. It is interesting that although the population in the River Bouhlou had a much more restricted distribution and lower abundance, the percentage of juveniles was far higher than in the River Laabid. Indeed, average $( \pm \mathrm{SD})$ values of shell length in the Bouhlou $(86.6 \pm 18.9 \mathrm{~mm})$ were much lower than in the Laabid (123.5 $\pm 12.5 \mathrm{~mm}$ ) (Sousa et al., 2016). Therefore, although restricted in distribution, a recruiting population is present in the River Bouhlou.

Both molecular markers (i.e. microsatellites and mtDNA) indicated a clear separation between the two basins, without recent past or current gene flow. From a conservation perspective, these two distinct units should be managed independently. In addition, the two populations have very low $F_{I S}$, which implies stable populations with high numbers of reproductive individuals. Because the surveys detected a very low abundance and restricted distribution, these results should be interpreted with some caution. In fact, the species decline may be very recent in both basins and still not imprinted on the genetic signal of the two populations analysed, given the extended life cycle of this species (maximum age more than 60 years using as a proxy the life cycle of Margaritifera auricularia; Nakamura et al., in press).

Aquatic invertebrates are grossly under-represented in assessments of conservation status and very few species are a target of management efforts (Collier, Probert, \& Jeffries, 2016; Sousa et al., 2015; Varandas et al., 2013). Despite this, many aquatic invertebrates are highly threatened by human activities and therefore their conservation should be a priority because they are responsible for important ecological functions and some of them can be as charismatic as mammals or birds. Margaritifera marocana is an example of a potentially charismatic aquatic invertebrate since it is critically endangered and is classified among the 100 most threatened species on Earth (Baillie \& Butcher, 2012). This freshwater mussel also has an interesting life cycle that needs a fish as a host, is long-lived, and is responsible for a range of ecosystem functions and services, including water purification (Sousa et al., 2016). Given these characteristics, and the increasing human pressure on the remaining populations, this species should be a target of urgent conservation action. The most acute threat is probably the increasing water demand for agriculture, industrial or domestic purposes, which in Morocco has been responsible for extensive decreases in river flow and turning many stretches of rivers from perennial to temporary (Schyns \& Hoekstra, 2014). This situation is particularly problematic for M. marocana because, like other Margaritifera species, it survives only in stretches with running water (Sousa et al., 2016). Other threats, such as loss and fragmentation of habitat, pollution, climate change and the introduction of invasive species are also important and should not be neglected (reviewed in Sousa et al., 2016).

In the particular case of the M. marocana population present in the River Bouhlou, the very restricted distribution suggests two opposing alternatives regarding its future conservation. On the one hand, any acute threat (pollution, increasing water demand or drought) will immediately impair the survival of the entire population. On the other, future measures (such as extension of the Tazzekka National Park to include the lower section of the Bouhlou; restoration of damaged stretches, including riparian vegetation; better management of river flow; and artificial rearing) are practical conservation options for this species. In addition, establishing national and international legislation (since the species is not legally protected in Morocco) and engaging local citizens are central to conserve $M$. marocana populations.

In conclusion, the discovery of this new population in the River Bouhlou confirms the occurrence of M. marocana in the Sebou basin, adding to the existing records of the species in the Oum Er Rbia basin (Sousa et al., 2016). This new population is crucial for maintaining future evolutionary processes and represents a distinct geographical and genetic identity. This emphasizes the importance of future conservation in the River Bouhlou being addressed independently, and for any management measures (in situ or ex situ) to take into account the intrinsic characteristics of this population.

\section{ACKNOWLEDGEMENTS}

This study was conducted within the scope of the project 'Biodiversity and conservation of the critically endangered freshwater mussels in Morocco: ecogeographic, genetic and physiological information', funded by Mohamed bin Zayed Species Conservation Fund (Reference 15256799), the project 'Breeding the most endangered bivalve on Earth: Margaritifera marocana', funded by IUCN SOS Save our Species fund (Reference 2015B-015), and by the Portuguese Foundation for Science and Technology (FCT) under grants SFRH/ BPD/108445/2015 (EF) and SFRH/BD/115728/2016 (MLL).

\section{ORCID}

Ronaldo Sousa (10 http://orcid.org/0000-0002-5961-5515

Manuel Lopes-Lima (10 http://orcid.org/0000-0002-2761-7962 


\section{REFERENCES}

Araujo, R., \& Ramos, M. A. (2000). A critical revision of the historical distribution of Margaritifera auricularia (Spengler, 1793) (Mollusca: Margaritiferidae) based on museum specimens. Journal of Conchology, 37, 49-59.

Araujo, R., Toledo, C., Van Damme, D., Ghamizi, M., \& Machordom, A. (2009). Margaritifera marocana (Pallary, 1918): A valid species inhabiting Moroccan rivers. Journal of Molluscan Studies, 75, 95-101.

Baillie, J. E. M., \& Butcher, E. R. (2012). Priceless or worthless? The world's most threatened species. London, UK: Zoological Society of London.

Belkhir, K., Borsa, P., Chikhi, L., Raufaste, N., \& Bonhomme, F. (2004). GENETIX 4.05, population genetics software for windows TM. Université de Montpellier II, Montpellier.

Clement, M., Posada, D., \& Crandall, K. A. (2000). TCS: A computer program to estimate gene genealogies. Molecular Ecology, 9, 1657-1659.

Collier, K. J., Probert, P. K., \& Jeffries, M. (2016). Conservation of aquatic invertebrates: Concerns, challenges and conundrums. Aquatic Conservation: Marine and Freshwater Ecosystems, 26, 817-837.

Earl, D. A., \& von Holdt, B. M. (2012). STRUCTURE HARVESTER: A website and program for visualizing STRUCTURE output and implementing the Evanno method. Conservation Genetics Resources, 4, 359-361.

Evanno, G., Regnaut, S., \& Goudet, J. (2005). Detecting the number of clusters of individuals using the software STRUCTURE: A simulation study. Molecular Ecology, 14, 2611-2620.

Froufe, E., Sobral, C., Teixeira, A., Sousa, R., Varandas, S. C., Aldridge, D., \& Lopes-Lima, M. (2014). Genetic diversity of the pan-European freshwater mussel Anodonta anatina (Bivalvia: Unionoida) based on CO1: New phylogenetic insights and implications for conservation. Aquatic Conservation: Marine and Freshwater Ecosystems, 24, 561-574.

Graf, D. L., \& Cummings, K. S. (2011). Freshwater mussel (Mollusca: Bivalvia: Unionoida) richness and endemism in the ecoregions of Africa and Madagascar based on comprehensive museum sampling. Hydrobiologia, 678, 17-36.

Hall, T. (1999). BioEdit: A user-friendly biological sequence alignment editor and analysis program for windows 95/98/NT. Nucleic Acids Symposium Series, 41, 95-98.

Jakobsson, M., \& Rosenberg, N. A. (2007). CLUMPP: A cluster matching and permutation program for dealing with label switching and multimodality in analysis of population structure. Bioinformatics, 23, 1801-1806.

Lopes-Lima, M., Froufe, E., Do, V. T., Ghamizi, M., Mock, K., Kebapci, U., .. Bogan, A. (2017). Phylogeny of most species rich freshwater bivalve family (Bivalvia: Unionida: Unionidae): Defining modern subfamilies and tribes. Molecular Phylogenetics and Evolution, 106, 174-191.

Lopes-Lima, M., Sousa, R., Geist, J., Aldridge, D. C., Araujo, R., Bergengren, J., ... Zogaris, S. (2017). Conservation status of freshwater mussels in Europe: State of the art and future challenges. Biological Reviews, 92, 572-607.

Lopes-Lima, M., Teixeira, A., Froufe, E., Lopes, A., Varandas, S., \& Sousa, R. (2014). Biology and conservation of freshwater bivalves: Past, present and future perspectives. Hydrobiologia, 735, 1-13.

Múrias dos Santos, A., Cabezas, M. P., Tavares, A. I., Xavier, R., \& Branco, M. (2016). tcsBU: A tool to extend TCS network layout and visualization. Bioinformatics, 32, 627-628.

Naimo, T. J., Damschen, E. D., Rada, R. G., \& Monroe, E. M. (1998). Nonlethal evaluation of the physiological health of unionid mussels: Methods for biopsy and glycogen analysis. Journal of the North American Benthological Society, 17, 121-128.

Nakamura, K., Cucala, L., Mestre, A. L., Mesquita-Joanes, F., Elbaile, E., Salinas, C., \& Muñoz-Yanguas, M. A. (in press). Modelling growth in the critically endangered freshwater mussel Margaritifera auricularia (Spengler, 1793) in the Ebro basin. Hydrobiologia.
Pallary, P. (1918). Diagnoses $d^{\prime} u n e$ cinquantaine de molusques terrestres nouveaux du Nord de l'Afrique. Bulletin de la Société d'Histoire Naturelle de l'Afrique du Nord, 9, 137-152.

Pallary, P. (1923). Descriptions de trois mollusques nouveaux du Maroc. Bulletin de la Société des Sciences Naturelles du Maroc, 3, 78-79.

Pallary, P. (1928). Notice sur seize mollusques nouveaux du Maroc découverts en 1926 et 1927. Journal de Conchyliologie, 72, 1-24.

Pritchard, J. K., Stephens, M., \& Donnelly, P. (2000). Inference of population structure using multilocus genotype data. Genetics, 155, 945-959.

Raymond, M., \& Rousset, F. (1995). GENEPOP (version 1.2): Population genetics software for exact tests and ecumenicism. Journal of Heredity, 86, 248-249.

Rosenberg, N. A. (2004). DISTRUCT: A program for the graphical display of population structure. Molecular Ecology Notes, 4, 137-138.

Sambrook, J., Fritsch, E. F., \& Maniatis, T. (1989). Molecular cloning: A laboratory manual. New York, NY: Cold Harbor Spring Press.

Schyns, J. F., \& Hoekstra, A. Y. (2014). The added value of water footprint assessment for national water policy: A case study for Morocco. PloS One, 9, e99705.

Shahin, M. (2002). Hydrology and water resources of Africa. New York, NY: Springer.

Sousa, R., Amorim, A., Froufe, E., Varandas, S., Teixeira, A., \& Lopes-Lima, M. (2015). Conservation status of the freshwater pearl mussel Margaritifera margaritifera in Portugal. Limnologica, 50, 4-10.

Sousa, R., Varandas, S., Teixeira, A., Ghamizi, M., Froufe, E., \& Lopes-Lima, M. (2016). Pearl mussels (Margaritifera marocana) in Morocco: Conservation status of the rarest bivalve in African fresh waters. Science of the Total Environment, 547, 405-412.

Strayer, D. L., Downing, J. A., Haag, W. R., King, T. L., Layzer, J. B., Newton, T. J., \& Nichols, S. J. (2004). Changing perspectives on pearly mussels, North America's most imperilled animals. Bioscience, 54, 429-439.

Varandas, S., Lopes-Lima, M., Teixeira, A., Hinzmann, M., Reis, J., Cortes, R., ... Sousa, R. (2013). Ecology of southern European pearl mussels (Margaritifera margaritifera): First record of two new populations on the rivers Terva and Beça (Portugal). Aquatic Conservation: Marine and Freshwater Ecosystems, 23, 374-389.

Walker, J. M., Bogan, A. E., Bonfiglio, E. A., Campbell, D. C., Christian, A. D., Curole, J. P., ... Hoeh, W. R. (2007). Primers for amplifying the hypervariable, male-transmitted COll-COI junction region in amblemine freshwater mussels (Bivalvia: Unionoidea: Ambleminae): Primer note. Molecular Ecology Notes, 7, 489-491.

Walker, J. M., Curole, J. P., Wade, D. E., Chapman, E. G., Bogan, A. E., Watters, G. T., \& Hoeh, W. R. (2006). Taxonomic distribution and phylogenetic utility of gender-associated mitochondrial genomes in the Unionoida (Bivalvia). Malacologia, 48, 265-282.

Zieritz, A., Bogan, A. E., Froufe, E., Klishko, O., Kondo, T., Kovitvadhi, U., ... Zanatta, D. T. (in press). Diversity, biogeography and conservation of freshwater mussels (Bivalvia: Unionida) in East and Southeast Asia. Hydrobiologia.

Zieritz, A., Lopes-Lima, M., Bogan, A., Sousa, R., Walton, S., Rahim, K., ... McGowan, S. (2016). Factors driving changes in freshwater mussel (Bivalvia, Unionida) diversity and distribution in peninsular Malaysia. Science of the Total Environment, 571, 1069-1078.

How to cite this article: Sousa R, Teixeira A, Santos A, et al. Oued Bouhlou: A new hope for the Moroccan pearl mussel. Aquatic Conserv: Mar Freshw Ecosyst. 2018;28:247-251. https://doi.org/10.1002/aqc.2825 